\title{
Correspondence
}

\section{Is propofol anticonvulsant or proconvulsant?}

To the Editor:

Excitatory events ranging from minor involuntary movements to opisthotonos and grand mal convulsions have been reported on induction of anaesthesia with propofol, but appear to be more common during recovery. ${ }^{1-3}$ In many, combinations of drugs were administered, making the incrimination of propofol difficult.

Our patient was a 25-yr-old man, with no epileptic history, for bilateral ligation of spermatic veins under epidural anaesthesia (500 $\mathrm{mg}$ lidocaine over $90 \mathrm{~min}$ ). The patient was sedated with an infusion of propofol at a rate of $3 \mathrm{mg} \cdot \mathrm{kg}^{-1} \cdot \mathrm{hr}^{-1}$. Following surgery, propofol was discontinued. Five minutes later, the patient developed tonic-clonic convulsions that recurred intermittently for four hours, despite $15 \mathrm{mg}$ diazepam, $500 \mathrm{mg}$ thiopentone and $1000 \mathrm{mg}$ diphenlyhydantoin. Electrolytes, blood sugar, CT scan, and ECG were normal.

The convulsions might have been secondary to lidocaine-induced systemic toxicity, ${ }^{4}$ which were masked intraoperatively by an anticonvulsant action of propofol. Propofol has even been previously used for management of drug-induced myoclonus, ${ }^{5}$ and for control of status epilepticus. ${ }^{6}$ However, the occurrence of withdrawal syndrome after propofol infusion that culminates in grand mal convulsions has been reported.? Excitatory CNS events such as myoclonus and opisthotonos have been reported in non-epileptic patients on induction of propofol anaesthesia, but appear to be more common during recovery. $2,7,8$ Previous reports have also shown that propofol can activate epileptogenic foci in epileptic patients. ${ }^{9,10}$

Propofol may exert dose-dependent anticonvulsant and proconvulsant actions. High concentrations depress both the cortex and subcortex acting as anticonvulsant: low concentrations may act as proconvulsant by inhibiting the inhibitory subcortex, resulting in "release" of neuronal hyperexcitability in the cerebral cortex. ${ }^{10,11}$

Anis Baraka MD FRCA (Hon)

Marie Aouad MD

American University of Beirut

Beirut - Lebanon

\section{REFERENCES}

1 Borgeat A, Dessibourg C, Popovic V, Meier D, Blanchard $M$, Schwander $D$. Propofol and spontaneous movements: an EEG study. Anesthesiology 1991; 74: 24-7.

2 Collier $C$, Kelly $K$. Propofol and convulsions - the evidence mounts. Anaesth Intensive Care 1991; 19: 573-5.

3 Committee on Safety of Medicines. Propofol and delayed convulsions. Current Problems 1992; 35: 2.

4 Brown DL, Ransom DM, Hall JA, Leicht CH, Scbroeder $D R$, Offord $K P$. Regional anesthesia and local anesthetic-induced systemic toxicity: seizure frequency and accompanying cardiovascular changes. Anesth Analg 1995; 81: 321-8.

5 Quinio $P$, Bouche $O$, Rossignol $B$, de Tinteniac $A$. Propofol in the management of myoclonus syndrome induced by chloralose poisoning (Letter). Anesthesiology 1995; 83: 875.

6 Mackenzie SJ, Kapadia F, Grant IS. Propofol infusion for control of status epilepticus. Anaesthesia 1990; 45: 1043-5.

7 Au J, Walker WS, Scott DHT. Withdrawal syndrome after propofol infusion. Anaesthesia 1990; 45: 741-2.

8 Saunders PRI, Harris MNE. Opiothotonus and other unusual neurological sequelae after outpatient anaesthesia. Anaesthesia 1990; 45: 552-7.

9 Hodkinson BP, Frith RW, Mee EW. Propofol and the electroencephalogram (Letter). Lancet 1987; 2: 1518.

10 Smith M, Smith SJ, Scott CA, Harkness WFJ. Activation of the electrocardiogram by propofol during surgery for epilepsy. Br J Anaesth 1996; 76: 499-502.

11 Cochran D, Price W, Gwinnutt CL. Unilateral convulsion after induction with propofol. Br J Anaesth 1996; 76: 570-2.

\section{Regional block cart is the way to go}

To the Editor:

Administration of peripheral nerve blocks are perceived to cause delays in the operating room. They can have a high failure rate if surgery is started without allowing for latency of onset. In an attempt to circumvent these problems we developed a mobile regional block cart (Figure) which allows us to perform regional blocks prior to the patient's arrival in the operating room, in a calm environment that allows sufficient time for the block to take effect. 